\title{
Significados e representações em produtos utilitários geek
}

\section{Meanings and representations in geek utilitarian products}

JERONIMO, Lucas Ribeiro

Universidade Federal de Campina Grande I lucas.ribeiro.jeronimo@gmail.com

MEDEIROS, Wellington Gomes de

Universidade Federal de Campina Grande I wellington.medeiros@ufcg.edu.br

\begin{abstract}
Resumo
Este artigo apresenta pesquisa sobre as qualidades semânticas e semióticas de produtos geek. O método de análise qualitativa incluiu a investigação dos produtos na dimensão semântica, com foco na função utilitária, e na dimensão semiótica, com foco na função simbólica. O texto define o que caracteriza as duas dimensões e descreve a análise de dois produtos da franquia Star Wars. Os resultados indicam que o método de análise pode favorecer a compreensão da interação significante dos usuários com os produtos.

\section{Abstract}

This paper presents a research on the semantic and semiotic qualities of geek products. The qualitative analysis includes the investigation of products on the semantic dimension - emphasizing the utilitarian function - and on the semiotic dimension - emphasizing the symbolic function. This work brings the definition of the two dimensions and the analysis of two products of the Star Wars franchise. Results indicate that the method can favor the understanding on the meaningful interaction of users with the products.
\end{abstract}

Palavras-chave: Semiótica. Semântica. Produtos geek. Design de produto.

Keywords: Semiotics. Semantics. Geek products. Product design. 


\section{INTRODUC̣ÃO}

De acordo com Bürdek e Van Camp (2006, p. 230) por muito tempo o interesse dos designers esteve voltado ao atendimento de funções práticas, questões de uso e atendimento de necessidades, quando as funções de comunicação eram exploradas em menor grau. Para Bürdek e Van Camp (2006, p. 31) os artefatos podem comunicar diversos aspectos:

[...] eles contam como foram constituídos, que tecnologia foi utilizada, de que contexto cultural têm origem. Eles nos contam também algo sobre os usuários, suas formas de vida, sobre se pertencem de verdade ou fingem pertencer a certos grupos, sobre atitude perante valores. O designer necessita, por um lado, entender esta linguagem, por outro deve fazer as coisas falarem por si sós.

Deste modo, cada produto incorpora diferentes funções, as quais se tornam perceptíveis no processo de uso e possibilitam a satisfação de certas necessidades. As funções mais importantes de um produto são: prática, estética e simbólica (LÖBACH, 2007, p. 55). A função prática está ligada a todos os aspectos fisiológicos do uso. Já a função estética é definida como um aspecto psicológico que emerge da percepção sensorial durante o uso; enquanto a função simbólica é determinada por todos os aspectos espirituais, psíquicos e sociais de uso (LÖBACH, 2007, p. 55-64).

A função simbólica é similar ao que Cardoso (2016) explica como transmissão de significado, destacando que as pessoas podem se vestir para transmitir mensagens, como por exemplo um médico ou policial, cujos trajes comunicam a classe profissional; mas, também se vestem para comunicar significados menos precisos, como pertencimento a um grupo social. A função simbólica ou de representação é inerente às características do signo, o principal objeto de estudo da semiótica. Segundo Susann Vihma (1995, p. 61), o signo é a relação entre uma coisa perceptível, sua representação e um sujeito interpretante. Ela afirma que um produto de design pode ser considerado um signo, pois quando é percebido, ele representa algo para aquele que o interpreta.

Assim como a comunicação da função simbólica apresenta uma área de estudo específica no design (semiótica), a comunicação da função prática dispõe da semântica como disciplina para sua exploração. A teoria do significado do artefato em uso, denominada de semântica do produto (KRIPPENDORFF, 2006) sugere uma abordagem não representacional, na qual o usuário irá reconhecer o que o produto é e para que serve pela interação com seus atributos. 
Medeiros (2014) fala que existem duas perspectivas para a abordagem dos significados: as qualidades representacionais e as não representacionais. Esta segunda corresponde à visão da semântica do produto, como mencionado, deriva da interação entre usuário e artefato. Já a primeira, dos significados representacionais, deriva da semiótica e compreende os artefatos como símbolos.

Os produtos utilitários geek são exemplos de objetos em que a dimensão simbólica e utilitária/prática está expressa em seus atributos. Alguns artefatos apresentam não somente qualidades representacionais do universo geek, como também qualidades não representacionais que comunicam sua função de uso.

Segundo Farias (2012) o termo geek é uma gíria que define pessoas peculiares ou excêntricas apaixonadas por tecnologia, jogos eletrônicos e cultura pop, que anseia pelo consumo de novidades tecnológicas e nutre uma satisfação em expressar gostos particulares.

Para Matos (2011), o estilo de vida nerd/geek parece ter sido assimilado pela indústria. Sites como Think Geek e Nerdstore são lojas online especializadas em vendas desse tipo de produto. O diferencial dessas lojas é a venda de produtos úteis que as pessoas assim como o público mais geral necessitam, mas com a caracterização geek presente. Por isso é pertinente o estudo desses objetos do ponto de vista do design de produtos, uma vez que a dimensão humana é recorrente nesses objetos por simbolizarem o estilo de vida dessas pessoas, bem como apresentarem dimensão funcional prática.

O presente estudo se apoia na justificativa de contribuir para os estudos do design e da semiótica do produto explorando novas perspectivas sobre objetos utilitários geek pouco estudados no meio acadêmico. O objetivo da pesquisa é abordar conceitos da semiótica e semântica no design aplicados à cultura pop, favorecendo a compreensão dos conceitos através de análises de produtos geek. Logo, seguindo a compreensão dos produtos como comunicação, entende-se que, no design, a semântica compreende a comunicação do uso dos objetos, enquanto a semiótica estuda o produto como representação, sendo os dois complementares. Em vista disso, a partir de uma abordagem qualitativa, foi realizada revisão de literatura sobre a semântica e semiótica do produto. Em seguida são demonstrados os conceitos abordados nos objetos geek.

\section{SEMÂNTICA DO PRODUTO}

De acordo com Löbach (2007, p. 89) destacam-se na produção industrial os seguintes critérios funcionalistas: "eliminação dos adereços "inúteis" e "supérfluos" dos produtos [...] Utilização de princípios construtivos técnico-físicos e técnico-econômicos[...] Renúncia à configuração de produtos com influências emocionais". 
Após o fim da Segunda Guerra Mundial, o funcionalismo prevaleceu na Alemanha. Quando, nos anos 1960, a HfG Ulm seguiu essa corrente do design à risca, desenvolvendo-a na teoria e na prática. A Ulm passou a se aproximar cada vez mais da indústria, o que fez com que muitas empresas utilizassem os princípios de design da escola, a exemplo da Braun (BÜRDEK; VAN CAMP, 2006).

A premissa "a forma segue a função" só foi mudar na Alemanha no início da década de noventa com a indústria automobilística, que reconheceu as limitações da homogeneização dos automóveis, acarretando a procura das empresas por diferenciar seus carros a partir da análise dos hábitos e desejos dos usuários (BÜRDEK; VAN CAMP, 2006). No resto do mundo, porém, o lema funcionalista tinha começado a ser questionado antes na década de sessenta, em paralelo ao surgimento da contracultura (HORN; MEYER; RIBEIRO, 2013). Após grande parte do século $X X$, sob influência do funcionalismo, o design começou a se voltar para seus usuários, e considerar as relações humanas e suas interações com os objetos. O design pós-moderno abre espaço para a dimensão semântica do produto, onde "a forma segue o significado" (KRIPPENDORFF, 1995).

Krippendorff e Butter fundaram a ideia de semântica do produto em 1989 em artigo publicado no periódico Design Issues daquele ano. O conceito é definido como uma pesquisa sistemática de como as pessoas interagem e atribuem significados aos artefatos, e de que maneira os designers podem se valer das respostas dos usuários para projetar produtos significantes (KRIPPENDORFF, 2006). Para indicar maneiras de como o designer deve abordar sistematicamente a semântica do produto, os autores sugerem, a partir da teoria do significado do artefato em uso, uma abordagem não representacional, que segue a linha de pensamento da teoria ecológica da percepção de Gibson (1977). Carvalho e Steil (2013) explicam que Gibson defende a percepção ambiente como direta, ou seja, a informação não está na mente de quem percebe e sim no ambiente, logo essa informação não parte de uma representação, mas é intrínseca ao ambiente.

Krippendorff (2006, p. 76) sugere ferramentas para análise, conceptualização e desenvolvimento de produtos. Segundo o autor, ao interagir com os produtos, as pessoas exercem modos de atenção nas etapas de uso. $\mathrm{O}$ primeiro modo de atenção é o reconhecimento, que é a identificação correta do que uma coisa é e para o que ela pode ser utilizada; o segundo é a exploração que precede o uso, nessa etapa o usuário irá descobrir o know-how, como manipular o artefato, o que ele pode ou não fazer com o objeto e como ele funciona; o terceiro e último passo é a confiança, nessa etapa o usuário está completamente à vontade com o produto, ele manipula o objeto de forma natural, não precisando mais pensar o como fazer para interagir com o produto (KRIPPENDORFF, 2006, p. 89-133). 
Considerando a compreensão de como o produto comunica sua função utilitária, acredita-se que as etapas de reconhecimento e exploração são as mais relevantes para o estudo. Esta pesquisa deu ênfase a essas duas etapas pois estão mais relacionadas à função utilitária, enquanto a etapa de confiança não foi discutida, uma vez que aborda um conhecimento já apreendido pelo usuário sobre o produto.

Por "reconhecimento", Krippendorff (2006) diz que se trata de reconhecer algo por seu tipo, e para que isso ocorra é necessário que o usuário tenha em seu repertório conhecimento sobre coisas semelhantes às reconhecidas, além do senso comum e de convenções sociais que podem facilitar o reconhecimento do produto. Próximo ao tipo ideal, ou seja, aquele mais comum, os artefatos são inequivocamente reconhecíveis. Logo, quanto menos típicos eles forem, mais difíceis de reconhecer eles serão.

Ainda na etapa de reconhecimento, podemos destacar o conceito referente à metáfora visual. "A metáfora é principalmente uma maneira de conceber uma coisa em termos de outra, e sua principal função é a compreensão" (LAKOFF; JOHNSEN, 2003, p.36). "As metáforas tornamse uma referência para os designers encontrarem ideias e para os usuários entenderem produtos" (YONGSUN, 2012, p. 31). "No contexto do uso, as metáforas permitem o reconhecimento de artefatos em termos de dimensões e características de outros artefatos mais familiares" (KRIPPENDORFF, 2006, p. 96). Portanto, as metáforas funcionam como referências para que os designers encontrem soluções para seus produtos, assim como auxiliam na compreensão dos objetos.

Krippendorff (2006) apresenta um exemplo de metáfora visual que informa tanto sobre o processo de design dos produtos quanto o entendimento dos usuários sobre esses artefatos. É o caso do computador de mão, hoje conhecido como tablet, e são reconhecidos pela familiaridade da escrita em um caderno. Um exemplo é o tablet que registra em tempo real o que é escrito sobre um papel comum com uma caneta especial, o produto pode ser visto na imagem a seguir.

A segunda etapa de interação do usuário com o produto trata da exploração. De acordo com Krippendorff (2006) é por meio da tentativa e erro que o usuário busca compreender como o produto pode ser utilizado. Para o presente estudo, nessa etapa destacam-se os conceitos de affordance e metonímia. Affordance é um conceito criado pelo psicólogo Gibson (1977) que consiste na relação entre uma pessoa ou animal com as propriedades presentes nos ambientes que comunicam como podem ser acionadas. Norman (1999) aplicou o termo para o design buscando adaptá-lo para a compreensão do uso dos produtos. 
Figura 1 - Caneta que transfere o que é escrito no papel para o tablet.

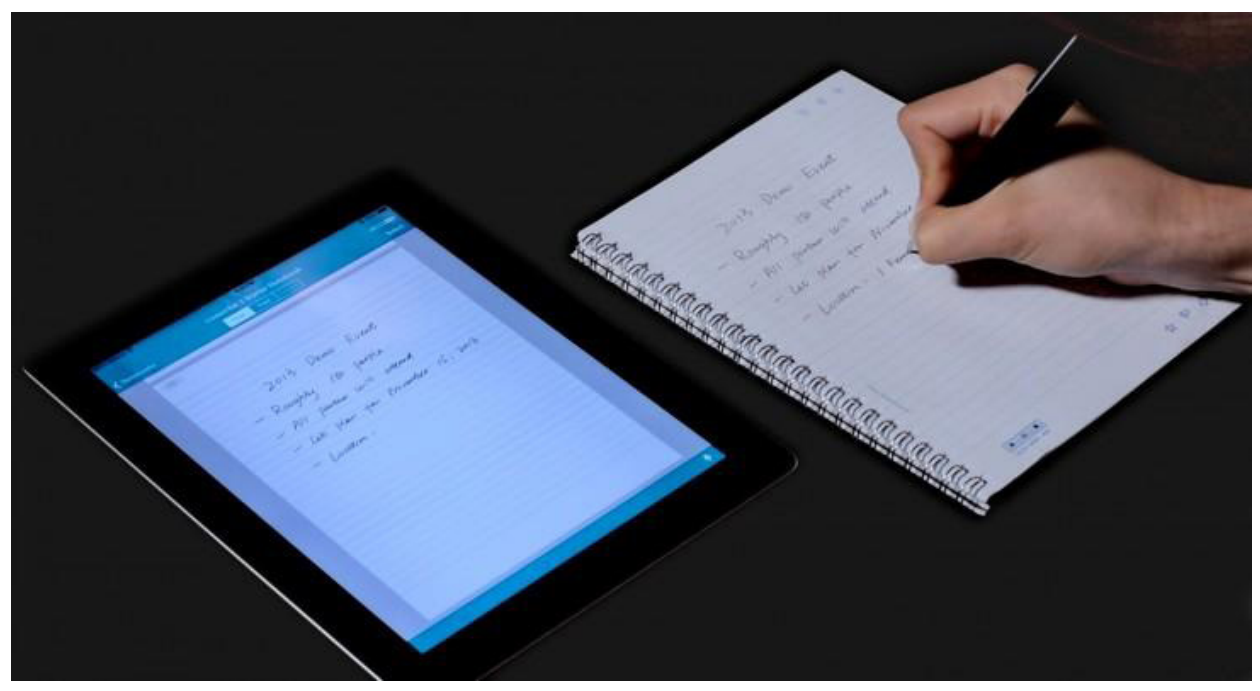

Fonte: Website Rolling Stone (2014).

Para Krippendorff (2006), affordances estão relacionados com o significado do artefato em uso, são percepções que indicam para que o artefato serve e o que pode ser feito com ele. O autor exemplifica que os botões, as alavancas, as alças, e os volantes tornam-se affordances quando podem ser vistos como apertáveis, móveis e giráveis. Logo, não basta apenas que esses affordances sejam utilizáveis, eles precisam comunicar que são utilizáveis, bem como a maneira correta que devem ser utilizados.

Metonímia é outro conceito relaciona à exploração do artefato. Se na metáfora existe uma correlação entre coisas que não necessariamente estão no mesmo domínio, na metonímia a relação ocorre entre coisas pertencentes ao mesmo domínio (GIBBS, 1994). Definida como a parte de um todo, a metonímia serve para proporcionar a compreensão através da referência (LAKOFF; JOHNSEN, 2003).

Podemos exemplificar a metonímia na caneca da franquia Star Wars, mais precisamente na caneca cuja morfologia é basicamente formada pelo capacete do Darth Vader. O produto é constituído por uma tampa na parte superior que, quando retirada, expõe a abertura do interior do objeto que funciona para colocar o líquido. Entretanto, sem a abertura na parte superior, a única identificação de que se trata de uma caneca é a alça. A alça é a metonímia, uma parte escolhida de um todo (caneca) para que fosse possível identificar a natureza do produto. No momento em que a alça comunica seu uso e sua função, ela opera no conceito de affordance.

Por isso é preciso ter cuidado na escolha da metonímia, pois existem muitas partes que podem representar o todo, mas a parte selecionada determina qual aspecto do todo é mais reconhecível. O quadro 1 relaciona as etapas de reconhecimento e exploração com os conceitos abordados anteriormente. 
Figura 2 - Caneca de café Darth Vader.

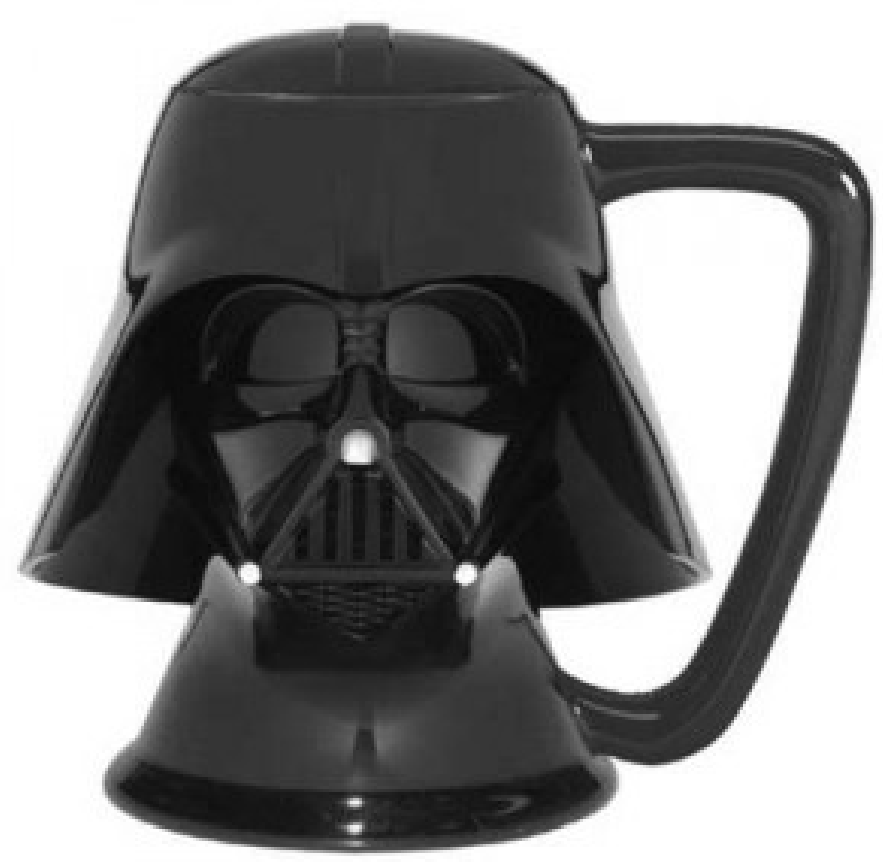

Fonte: Website Ownzee (2011).

Quadro 1 - Etapas de reconhecimento e exploração na semântica do produto.

\begin{tabular}{|c|c|}
\hline Reconhecimento & Exploração \\
\hline Tipo ideal & Affordances \\
Metáforas visuais & Metonímia \\
\hline
\end{tabular}

Fonte: Elaborado pelo autor com base em Krippendorff (2006).

As definições de produtos utilitários e funções práticas auxiliam na compreensão da dimensão na qual a virada semântica de Krippendorff se instaura, isto é, a maneira que o produto comunica seu uso, sua função utilitária para o usuário, e os significados recorrentes dessa interação. Significados que por serem inerentes aos artefatos são não-representacionais.

\section{SEMIÓTICA DO PRODUTO}

Löbach (2007) mostra que, com o advento das máquinas, o número de objetos de uso com predomínio de funções práticas se multiplicou, tornando-se acessíveis para uma grande camada da população. Com o mercado repleto de produtos utilitários similares, os designers se voltaram novamente às funções de representação para fazerem seus produtos se diferenciarem. 
Um país que sempre deu atenção às múltiplas possibilidades do design e não seguiu a linha funcionalista que perdurou na Alemanha, é a Itália. Se a Braun é uma empresa que representa o design alemão, pode-se dizer o mesmo da Alessi com relação ao design italiano. Compreendendo que os objetos da Alessi são exemplos de produtos que comunicam não só sua função prática como sua função simbólica, com ênfase na segunda, entende-se que esses artefatos se encaixam nos tipos de produtos que comunicam seus significados de maneira representacional. Como por exemplo, podemos citar o suporte magnético de clipe (figura 3) no qual a forma representa um pássaro e a maneira que os clipes de papel magnetizados estão colocados lembram asas do animal. O mesmo ocorre com o amassador de pimenta Piccantino (figura 4) que remete à tradição do amuleto de boa sorte da pimenta vermelha de Napoli, além de representar diretamente o condimento dentro do recipiente.

Figura 3 - Suporte de clipe de papel projetado por Rodrigo Torres.

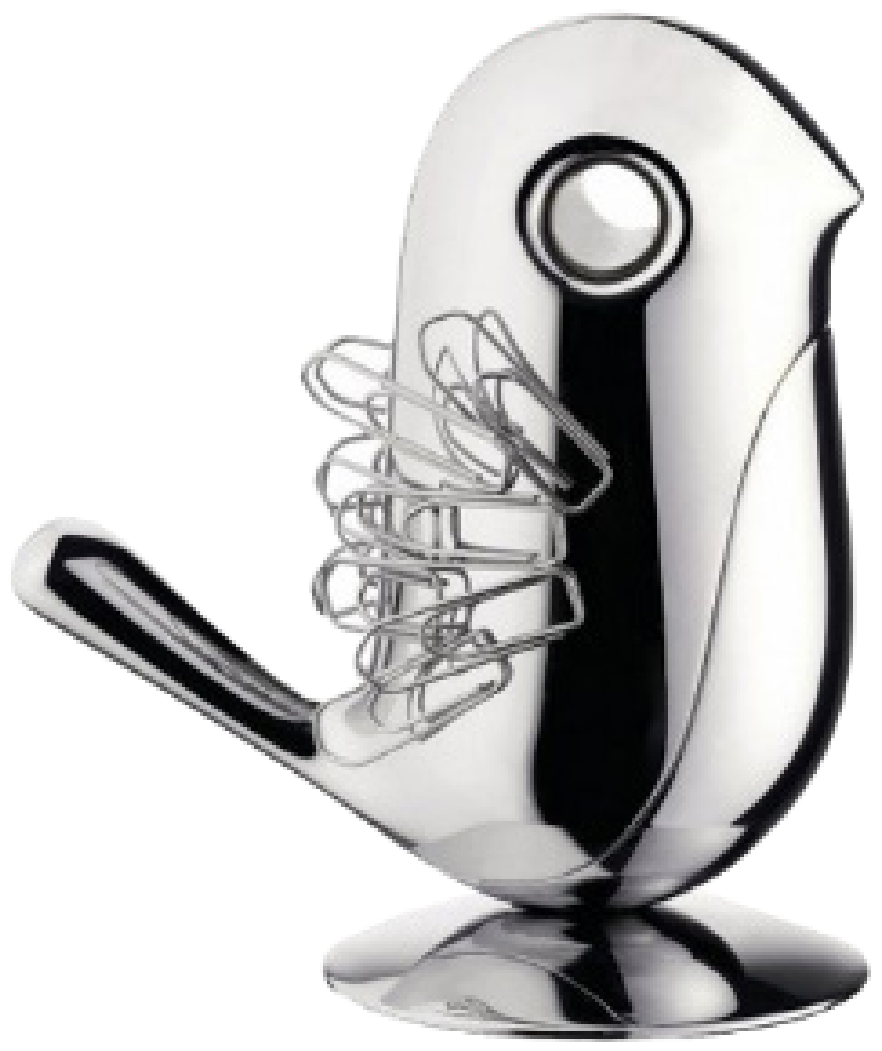

Fonte: Website Alessi (2017).

A concepção de produtos como signos advém da disciplina que estuda os objetos enquanto representações: a Semiótica. Algumas definições para Semiótica incluem: "[...] denominada teoria dos signos, é uma ciência dedicada ao estudo de toda e qualquer linguagem capaz de produzir sentido, significação e de comunicar" (ABREU; MONTEIRO, 2011). "A semiótica emergiu como área de interrogação teórica nos anos que precederam a I Grande Guerra" (FIGUEIREDO, 2009). A teoria semiótica peirceana estabelece os parâmetros teóricos nesta pesquisa, pois além de ser exaustivamente validada em diversas áreas do conhecimento (DIAS, 2013), acredita-se que para esse estudo a sua concepção de signo se adequa melhor ao design de produto. 
Figura 4 - Amassador de pimenta Piccantino projetado por Jim Hannon-Tan.

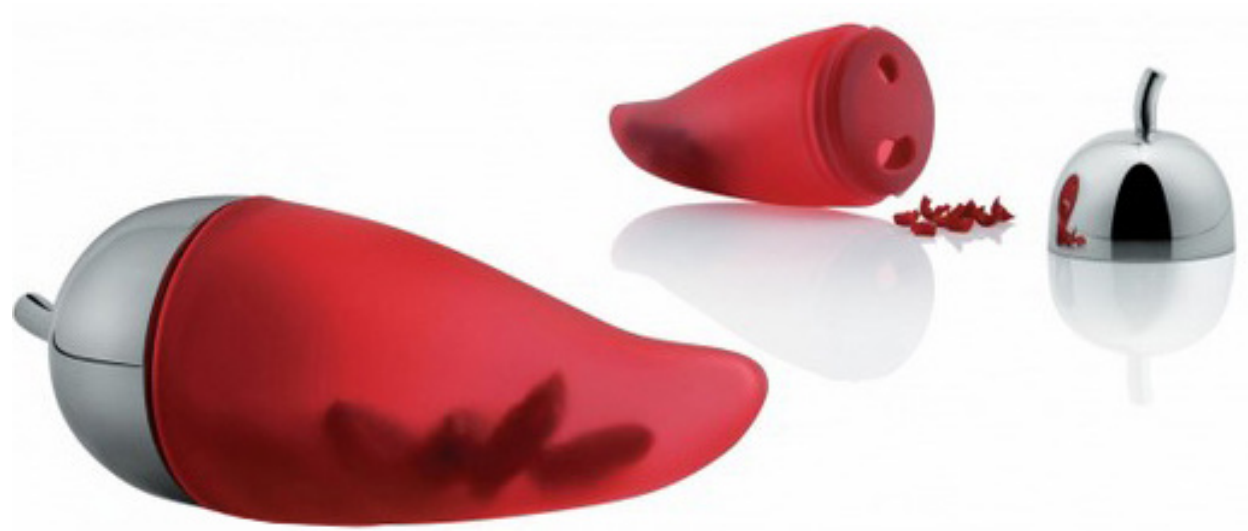

Fonte: Website Alessi (2017).

Santaella (2001) escreve que, para Peirce, qualquer coisa que substitui outra coisa para um intérprete é uma representação ou signo. Ela dá o exemplo de um retrato, que representa uma dada pessoa para a concepção do seu reconhecimento por alguém. Aquilo que constitui o signo é a relação triádica entre três termos (figura 5): o fundamento do signo, seu objeto e seu interpretante (SANTAELLA, 2001).

Figura 5 - Relação triádica que constitui o signo na semiótica peirceana.

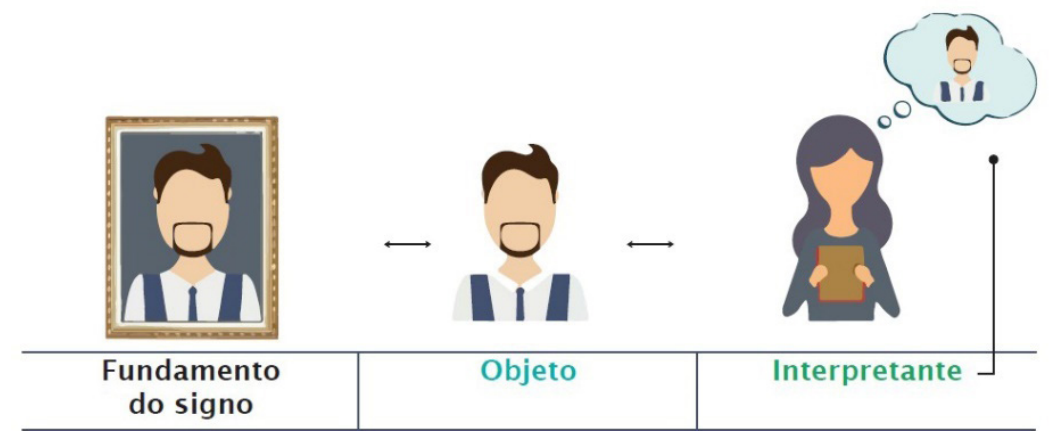

Fonte: Elaborado pelo autor.

O fundamento do signo consiste em uma propriedade ou aspecto do signo; o objeto é a coisa a qual o fundamento representa; o interpretante é o efeito ou ideia produzido na mente do receptor. A essa relação triádica, Peirce chamou de semiose, uma produção de significados, ou seja, o processo por meio do qual uma coisa se torna para alguém signo de outra coisa (PEREIRA, 2011).

O objeto presente na semiose é divido em dois tipos: objeto imediato e objeto dinâmico. Santaella (2001), explica que o objeto imediato é o modo como o objeto dinâmico se apresenta, está indicado ou está representado no próprio signo. Sendo assim, o objeto imediato está presente no signo e funciona como um recorte do objeto dinâmico que está fora do signo e é mais extenso. Sobre interpretante, a autora fala que ele é dividido em três: o interpretante imediato, o interpretante dinâmico e o interpretante final. Segundo ela, o 
interpretante imediato é aquilo que o signo está apto a produzir como efeito, já o interpretante dinâmico é o que efetivamente é interpretado pelo receptor do signo. Uma vez que este estudo não inclui a interação e interpretação de terceiros, o nível do interpretante não será abordado nesse trabalho.

O objeto dinâmico e o interpretante dinâmico estão fora do signo, pois o objeto dinâmico é todo o contexto ao qual o objeto imediato reporta, enquanto o interpretante dinâmico é o efeito produzido na mente do intérprete (figura 6). O interpretante final acontece quando todas as intepretações possíveis são feitas, logo não é possível de ser alcançado uma vez que não é concebível mensurar todas as intepretações possíveis.

Figura 6 - Relação triádica que constitui o signo na semiótica peirceana.

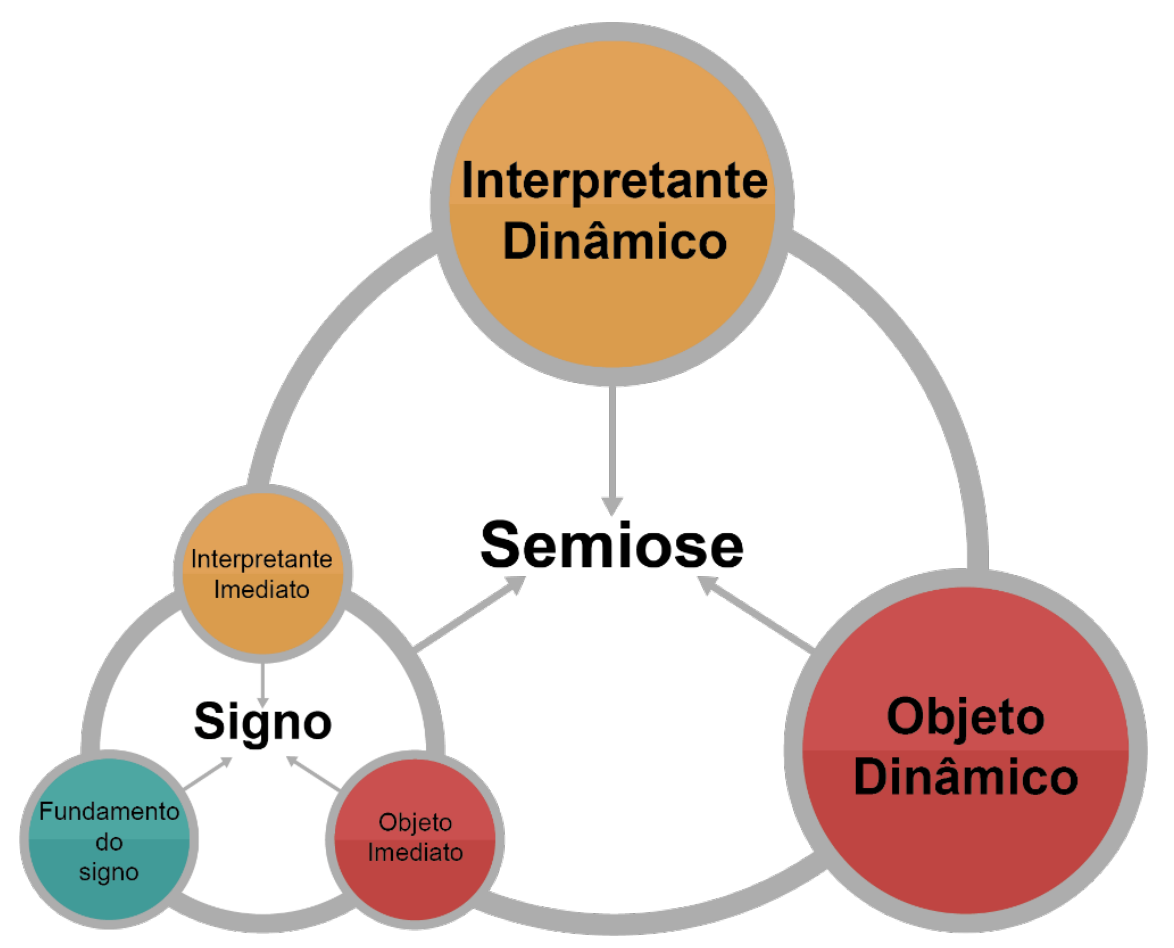

Fonte: Elaborado pelo autor.

Para o estudo dos produtos utilitários geek nesta pesquisa, foi estabelecido que: o fundamento do signo são as propriedades que definem o artefato; o objeto imediato é o recorte do filme que está presente no produto, sendo penas aquilo que está representado e incorporado nos atributos físicos do produto; o objeto dinâmico é o filme como um todo; o interpretante imediato é aquilo que o produto está apto a produzir como efeito; e o interpretante dinâmico é a ideia gerada na mente do intérprete ao fazer as associações e chegar a conclusões sobre o produto. Na figura 7 a seguir é possível ver o processo de semiose em uma luminária com referência à franquia Star Wars, mais precisamente ao cartaz original do primeiro filme da saga lançado em 1977. 
Figura 7 - Semiose detalhada na luminária geek de Star Wars.

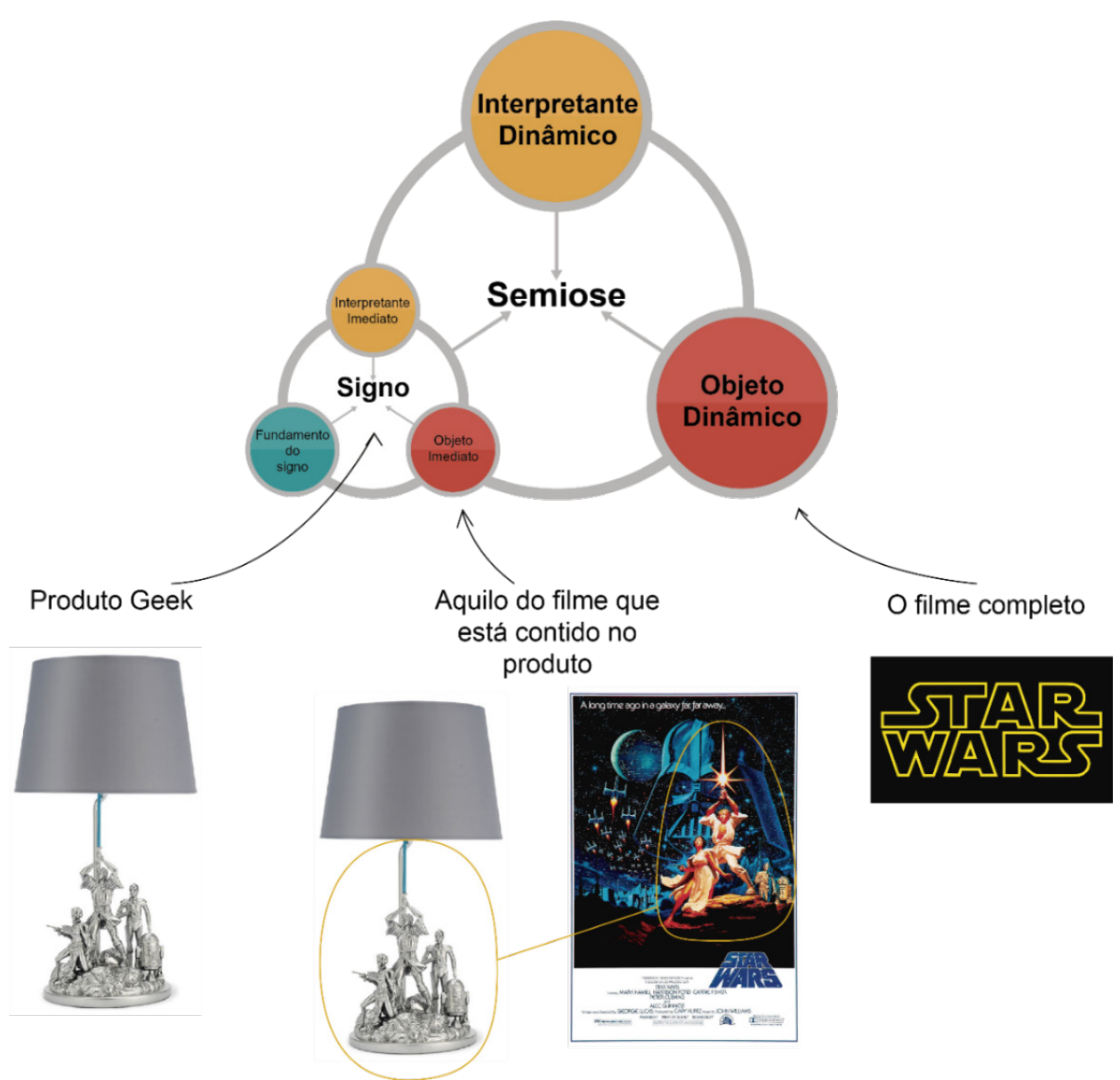

Fonte: Elaborado pelo autor.

Peirce dividiu e classificou as relações que o signo opera em três tricotomias: com o seu fundamento do signo, com o objeto e com o interpretante. A primeira tricotomia envolve a natureza material do signo, seu fundamento, se dá em relação ao signo consigo mesmo por uma qualidade, uma singularidade ou uma lei geral. A segunda tricotomia diz respeito à relação do signo com seu objeto. Desta forma, um signo pode ser um ícone, um índice ou um símbolo (WARTHA; REZENDE, 2016). A terceira tricotomia relaciona o signo com o interpretante, e, como mencionado anteriormente, não será levado em consideração neste trabalho.

A classificação do signo com o seu objeto é a tricotomia mais explorada dentre os estudos de Peirce. No design, as concepções de ícone, índice e símbolo podem ser encontradas nos produtos, onde comumente são estudadas através da perspectiva da semiótica do produto. No livro Semiótica, informação e comunicação, Coelho Neto (1996, p. 58) define essa segunda tricotomia. Para ele, ícone é um signo que tem alguma semelhança com o objeto representado, como por exemplo, a escultura de uma mulher e a fotografia de um carro. Já o índice, ele define como sendo signo que se refere ao objeto denotado em virtude de ser diretamente afetado pelo objeto, ele dá exemplo da fumaça como signo indicial de fogo. Fidalgo e Gradim (2005) ilustra essa ideia com o exemplo 
de um relógio como sendo índice do tempo. Coelho Neto (1996) descreve o símbolo como um signo que se refere ao objeto denotado em virtude de uma associação de ideias produzida por convenção. Fidalgo (2005) argumenta que os emblemas, as insígnias e os estigmas são exemplos de símbolos.

Entende-se, portanto, que o objeto imediato presente nos atributos físicos de produtos utilitários geek, é um recorte do filme, e se apresenta de maneira icônica, indicial e/ou simbólica. Logo, define-se neste estudo que os produtos utilitários geek encontram-se entre esses dois polos: de um lado a função de representação da cultura geek em seus atributos físicos, e do outro a função utilitária prática que responde ao uso propriamente dito. Logo, são produtos complexos que podem gerar diversos significados para seus usuários e contemplam várias áreas de necessidades, sejam subjetivas ou práticas. Os produtos geek podem ser definidos pela seguinte perspectiva:

[...] acredita-se que um produto (objeto de uso), além de servir a fins utilitários, carrega consigo atributos estéticos e simbólicos. No entanto, devido ao seu caráter utilitário, está inserido em um contexto corriqueiro, cotidiano. E, assim, sua relação com o sujeito, é constante e imediata [...] Desse modo, a interação do sujeito com o objeto se dá em nível mais profundo indo além dos interesses práticos e imediatos [...] Essa interação ocorre a partir de diversos fatores, tanto racionais, quanto emocionais, os quais irão afetar o sujeito de modo significativo (QUEIROZ; CARDOSO; GONTIJO, 2015, p. 4).

\section{SEMÂNTICA E SEMIÓTICA DOS PRODUTOS GEEK}

Os produtos utilitários geek são bons exemplos de objetos aos quais os conceitos apresentados - a semântica relacionada à dimensão utilitária e de uso, e a semiótica às suas qualidades simbólicas - podem ser observados. Nesses artefatos entende-se que a função simbólica está relacionada ao universo geek, mais precisamente filmes aos quais fazem referência. Já a função utilitária compreende a comunicação do que o produto é, para que serve e como deve ser utilizado. Star Wars é uma das maiores franquias da cultura pop, por isso foram escolhidos produtos que representassem seus filmes: a água tônica da marca blk e o faqueiro X-Wing do site Think Geek, que podem ser vistos na imagem a seguir. 
Figura 8 - Produtos utilitários geek para análise.

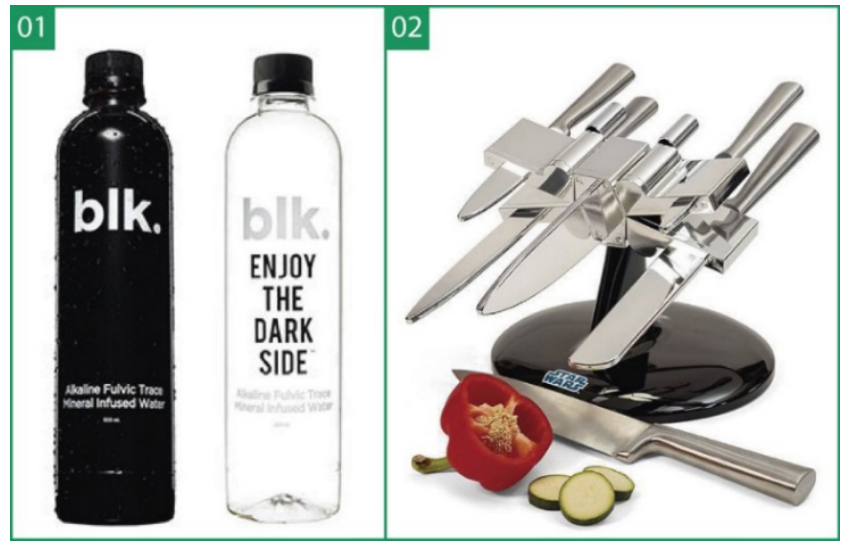

Fonte: Elaborada pelo autor.

\subsection{Produto Geek 01}

Figura 9 - Embalagem blk. water black.
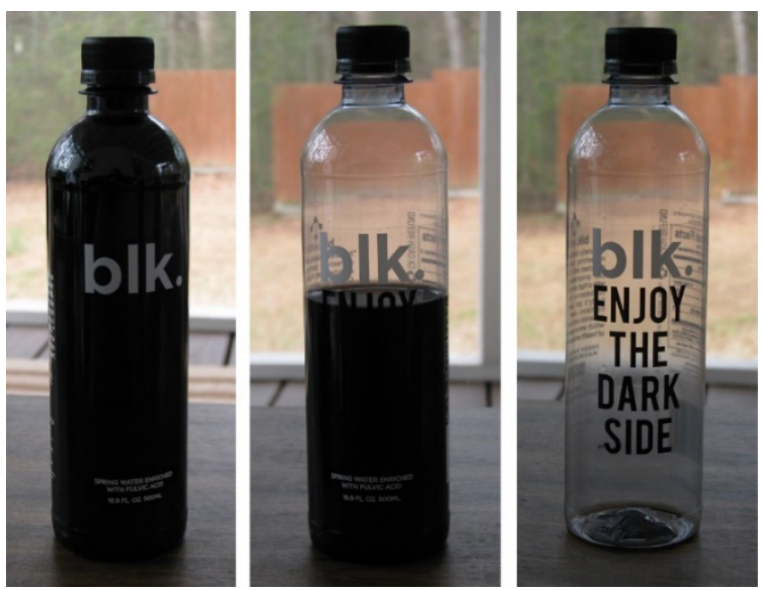

Fonte: Website Getblk (2018).

\subsubsection{Análise semântica}

A embalagem se assemelha ao tipo ideal de outras embalagens de água ao apresentar uma orientação vertical e cilíndrica no corpo, além da tampa em sua extremidade superior. A metáfora visual está presente na cor da água que se torna a cor da embalagem quando cheia, logo, assim como a embalagem muda quando está com o líquido, quem a bebe também irá mudar ao receber seus nutrientes. Podemos identificar dois affordances: a forma cilíndrica que indica de que maneira o produto deve ser pego, e a tampa que acompanha a forma cilíndrica, indicando que é preciso girá-la para abrir. A tampa pode ser identificada como metonímia, pois é um elemento comum às a embalagens de garrafa plástica de água. 
Em relação à embalagem o produto é facilmente reconhecido pelo que é e para que serve. Sem a leitura das informações na garrafa, a identificação do líquido como uma bebida energética não é tão facilmente reconhecido devido à especificidade da cor.

\subsubsection{Análise semiótica}

O objeto imediato está no produto como um grafismo em texto referência ao lado negro da força, elemento da narrativa dos filmes da franquia Star Wars que caracteriza o "mal". O objeto dinâmico é a franquia Star Wars como um todo e o embate entre o lado da luz e o lado negro em sua trama. O objeto imediato se apresenta de maneira icônica pela semelhança da cor do líquido e do texto na embalagem com o preto que é característico da indumentária dos personagens que são do lado negro da força no filme. Podemos identificar índice no texto que aparece na medida que o líquido é esvaziado da garrafa, passando a mensagem para aproveitar o dark side, além das outras informações técnicas na embalagem que também funcionam como índice. O signo simbólico é a transmissão da ideia de que ao beber o líquido a pessoa está incorporando o lado negro. O próprio líquido se torna representação do lado negro, com conotações negativas nos filmes, mas que na embalagem carrega as qualidades da água tônica e suas vantagens nutricionais. Uma contradição que adiciona ao produto uma dimensão lúdica.

A análise indica ser necessário que o repertório do usuário sobre a franquia Star Wars ultrapasse o conhecimento superficial dos filmes, contemplando detalhes narrativos sutis, para que o signo presente na frase seja apreendido, uma vez que podemos deduzir que o texto não é tão facilmente reconhecível quanto, por exemplo, uma representação gráfica do capacete do Darth Vader. 


\subsection{Produto Geek 02}

Figura 10 - Faqueiro X-Wing.

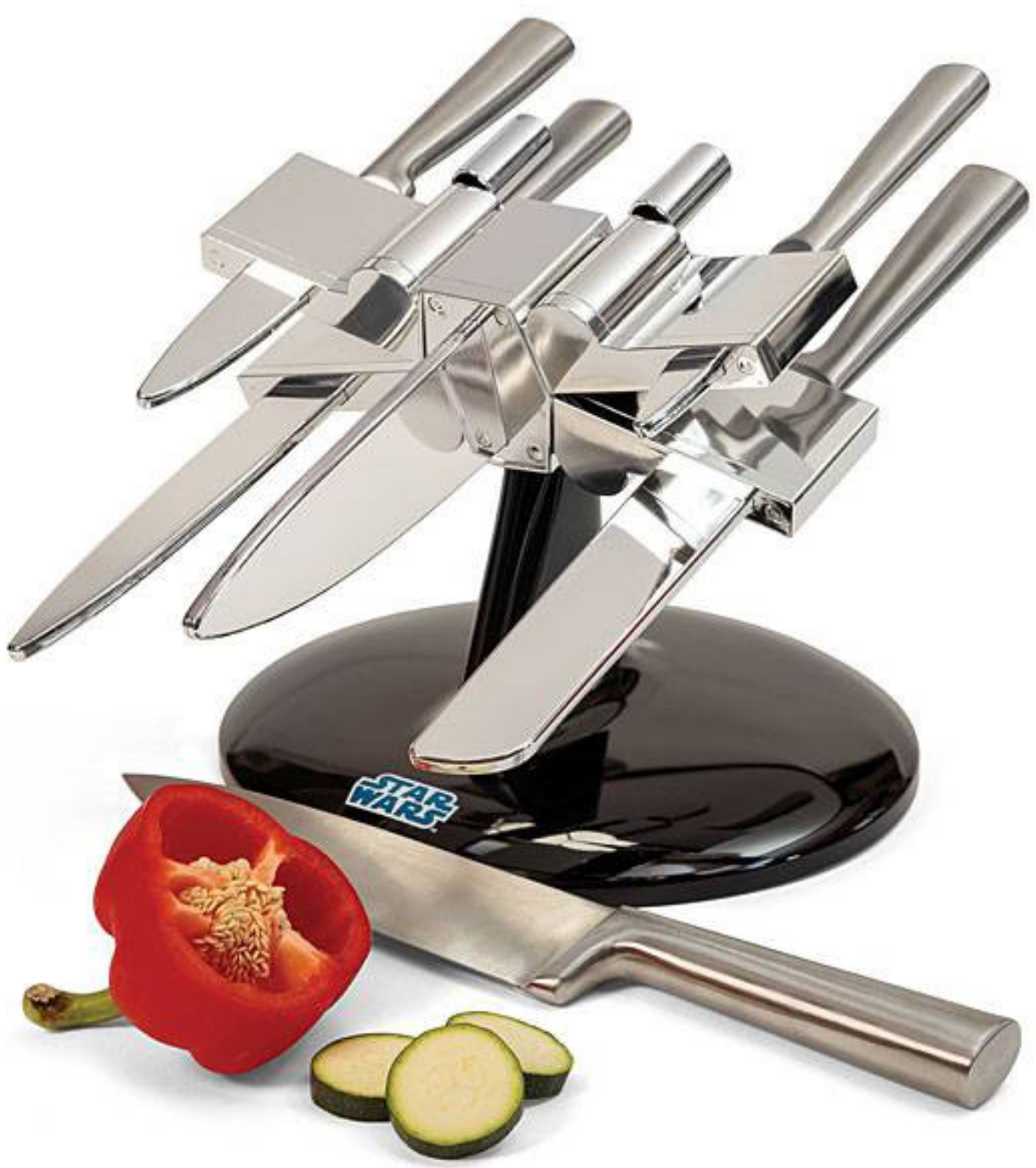

Fonte: Website Thinkgeek (2017).

\subsubsection{Análise semântica}

O produto se assemelha aos chamados knife blocks, faqueiros onde as lâminas das facas ficam encaixadas e guardadas inclinadas, com o cabo ficando visível exteriormente a forma do produto. Apenas com a equivalência da forma de guardar as facas, o objeto apresenta alto grau de originalidade, comprometendo a inteligibilidade da forma de uso. A metáfora visual pode ser observada na semelhança entre a posição das facas e a forma da nave X-Wing de Star Wars. O affordance pode ser identificado nos vazados e as formas diferentes das lâminas no produto que indicam que determinada faca tem um local específico para ser guardada. Quando as facas estão inseridas no objeto os cabos configuram-se metonímias que o caracterizam como faqueiro, se retiradas a compreensão do que é o produto é dificultada. 
Sem as facas, apenas os vazados na parte posterior podem ser reconhecidos como metonímia. Porém, as bainhas na parte frontal são affordance que favorecem o reconhecimento do objeto pelo o que ele é para que serve.

\subsubsection{Análise semiótica}

Figura 11 - Nave X-Wing.

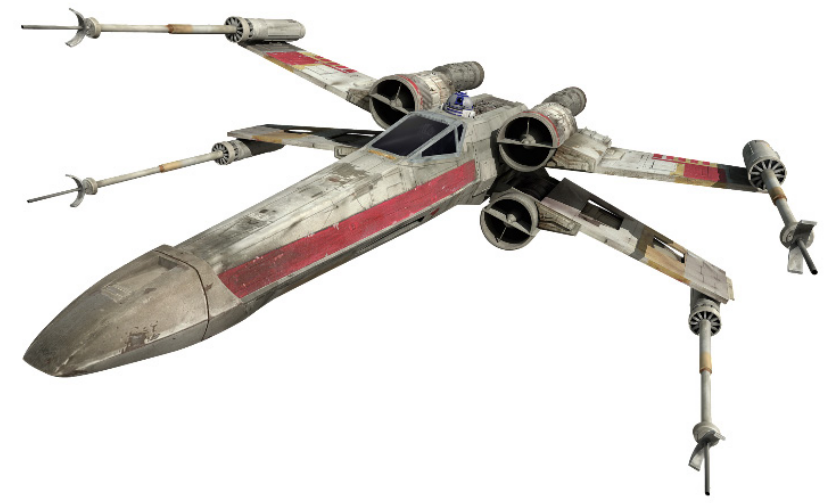

Fonte: Website Starwars. wikia (2018).

O objeto imediato é a forma da nave X-Wing. O objeto dinâmico é toda a franquia Star Wars e as naves de combate. O objeto imediato se apresenta de maneira icônica, assim como a metáfora por ter semelhança com a forma da nave $X$-Wing (figura 11). A nave tem quatro lançadores de mísseis, que foram adaptados para quatro espaços de facas no objeto. O espaço destinado à faca localizada no centro do produto se assemelha ao corpo da nave. Há também quatro elementos estéticos na parte posterior que representam as turbinas da nave (figura 12).

Figura 12 - Vista posterior faqueiro X-Wing.

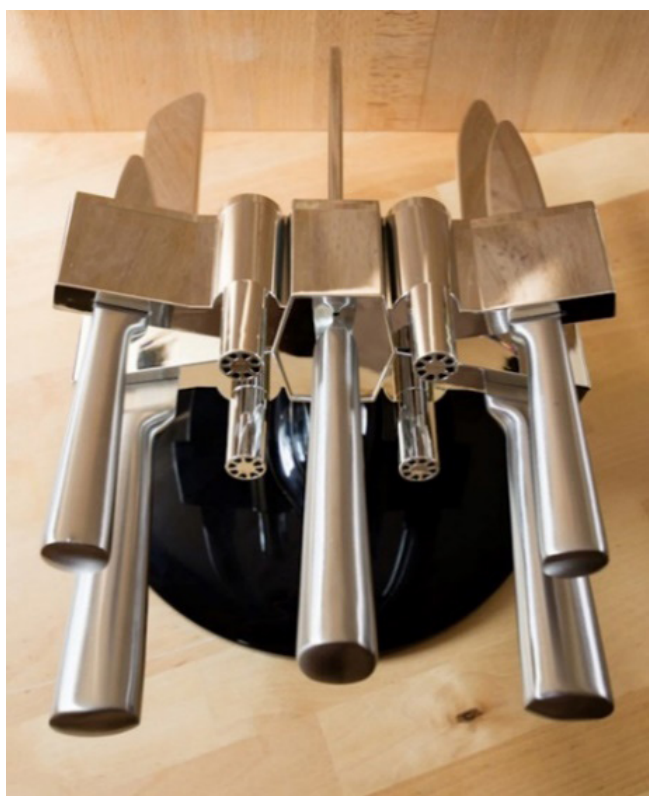

Fonte: Website Kaveyeats (2018). 
Os índices, bem como os affordances são as bainhas das facas presentes no produto, e as aberturas com tamanhos diferentes para os distintos tipos de facas. O objeto imediato se apresenta de maneira simbólica ao representar a agressividade da função mesma da faca e da função de ataque da nave em analogia aos locais onde são guardadas as facas.

A forma da nave X-Wing é bem representada no produto e se confunde com a função utilitária. Para reforçar a semelhança icônica com o objeto imediato ainda há os elementos estéticos cilíndricos que remetem às turbinas da nave. Portanto, o reconhecimento da função utilitária é prejudicado uma vez que as facas não estão encaixadas no produto, porém a ausência das facas não prejudica a função simbólica.

\section{CONSIDERAC̣ÕES FINAIS}

Ao caracterizar as dimensões utilitária e simbólica dos produtos, a semântica e a semiótica apresentam-se como áreas que contribuem para o design e que podem ser utilizadas para desenvolver produtos mais significantes, com maior valor agregado que possibilitam diferentes relações com os usuários, estejam elas associadas ao utilitário ou ao simbólico.

Os produtos geek são exemplos de objetos nos quais os conceitos apresentados podem ser explorados de forma didática por proporcionar a visualização em seus atributos acerca das representações que eles referenciam. Dessa maneira, é possível analisar como o universo geek está presente e se relaciona com a função prática do objeto.

Sendo áreas afins, a semântica e a semiótica estão fundamentadas em conceitos equivalentes, como pode ser observado nas análises. $\mathrm{O}$ ícone e a metáfora podem ser correlacionados por apresentarem em suas definições a relação de similaridade entre duas coisas diferentes. Já o índice e o affordance, quando abordados em produtos, também são parecidos por apresentarem a indicação de o que pode ser feito com ele.

Este estudo demonstrou que a investigação das qualidades significantes dos produtos geek, a partir da identificação tanto dos significados diretos e objetivos da função e do uso quanto aqueles relacionados às possibilidades de representação, favorece a compreensão do interesse e da interação de usuários por este tipo específico de produto. 


\section{REFERÊNCIAS}

ABREU, Joel; MONTEIRO, Silvana. Matrizes da linguagem e a organização virtual do conhecimento. Ciência da Informação, Brasília, v. 39, n. 2, p. 9-26, 2011.

BÜRDEK, Bernhard E.; VAN CAMP, Freddy. Design: história, teoria e prática do design de produtos. São Paulo: Editora Edgard Blücher, 2006.

CARVALHO, Isabel Cristina de Moura; STEIL, Carlos Alberto. Percepção e ambiente: aportes para uma epistemologia ecológica. REMEA, Rio Grande, RS, n. esp. p. 59-79, mar. 2013.

DIAS, Almerinda Tereza Bianca Bez Batti. Semiótica peirceana: método de análise em pesquisa qualitativa. Indagatio Didactica, Aveiro, v. 5, n. 2, 2013.

FARIAS, Diego Assad. Plano de negócio: empresa SuitUP! 2012. Trabalho de Conclusão de Curso (Graduação em Administração) - Universidade Federal do Rio Grande do Norte, Natal, 2012.

FIDALGO, António Carreto; GRADIM, Anabela. Manual de semiótica. [Lisboa]: UBI, 2005. Disponível em: https://ubibliorum.ubi.pt/ bitstream/10400.6/714/1/fidalgo-gradim-manual-semiotica-2005.pdf. Acesso em: 5 mar. 2018.

FIGUEIREDO, João Filipe Dias. A expressão simbólica do produto: um contributo conceptual-analítico para informar a prática do design do produto. 2009. Dissertação (Mestrado em Design Industrial Tecnológico) Universidade da Beira Interior, Covilhã, 2009.

GIBBS, Raymond W. The poetics of mind: figurative thought, language, and understanding. Cambridge: Cambridge University Press, 1994.

GIBSON, James J. The theory of affordances. In: SHAW, Robert; BRANSFORD, John (ed.). Perceiving, acting, and knowing: toward an ecological psychology. Hillsdale: Lawrence Erlbaum Associates, Publishers, 1977. p. 67-82.

HORN, Bibiana Silveira; MEYER, Guilherme Corrêa; RIBEIRO, Vinicius Gadis. Um olhar sobre três maneiras de pensar o design. In: SEPESQ SEMANA DE EXTENSÃO, PESQUISA E PÓS-GRADUAÇÃO DO CENTRO UNIVERSITÁRIO RITTER DOS REIS, 9., 2013, Porto Alegre. Anais [...]. Porto Alegre, 2013. Disponível em: https://www.academia.edu/24217515/Um_olhar_sobre_ tr\%C3\%AAs_maneiras_de_pensar_o_design. Acesso em: 5 mar. 2019. 
KRIPPENDORFF, Klaus. Redesigning design; an invitation to a responsible future. In: KAHKOKALLIO, P.; VIHMA, S. (ed.). Design: pleasure or responsibility. Helsinki: University of Art and Design, 1995. p. 138-162.

KRIPPENDORFF, Klaus. The semantic turn: a new foundation for design. Bota Ranton: CRC Press, 2006.

LAKOFF, George; JOHNSEN, Mark. Metaphors we live by. London: The University of Chicago Press, 2003. Disponível em: http://shu.bg/tadmin/ upload/storage/161.pdf. Acesso em: 5 ago. 2018.

LÖBACH, Bernd. Design industrial. São Paulo: Edgard Blücher, 2007.

MATOS, Patrícia. O nerd virou cool: identidade, consumo midiático e capital simbólico em uma cultura juvenil em ascensão. In: CONGRESSO DE CIÊNCIAS DA COMUNICAÇÃO NA REGIÃO SUDESTE-INTERCOM, 16., 2011, São Paulo. Anais [...]. São Paulo, 2011.

MEDEIROS, Wellington Gomes. Meaningful interaction with products. Design Issues, Chicago, v. 30, n. 3, p. 16-28, 2014.

NETO COELHO, José Teixeira. Semiótica, informação e comunicação. São Paulo: Perspectiva, 1996. v. 5.

NORMAN, Donald A. Affordance, conventions, and design. Interactions, New York, v. 6, n. 3, p. 38-43, 1999.

PEREIRA, Carla Patrícia de Araújo. A cor como espelho da sociedade e da cultura: um estudo do sistema cromático do design de embalagens de alimentos. 2011. Tese (Doutorado em Design e Arquitetura) - Faculdade de Arquitetura e Urbanismo, Universidade de São Paulo, São Paulo, 2011.

QUEIROZ, Shirley Gomes; CARDOSO, Cristina Luz; GONTIJO, Leila Amaral. Design Emocional e Semiótica: caminhos para obter respostas emocionais dos usuários. Estudos em Design, Rio de Janeiro, v. 17, n. 1, 2015.

SANTAELLA, Lucia. Matrizes da linguagem e pensamento: sonora, visual, verbal: aplicações na hipermídia. São Paulo: Editora Iluminuras, 2001.

VIHMA, Susann. Products as representations: products as representation: a semiotic and aesthetic study of design products. Espoo: UIAH Helsinki, Finland, 1995. 
WARTHA, Edson José; REZENDE, Daisy de Brito. Os níveis de representação no ensino de química e as categorias da semiótica de Peirce. Investigações em Ensino de Ciências, Porto Alegre, v. 16, n. 2, p. 275-290, 2016.

YONGSUN, Bae. Design through metaphor. 2012. Dissertação (Master's in Industrial and Strategic Design) - Aalto University School of Arts, Espoo, Helsinki, Finland, 2012.

Data de submissão: 2018-09-25

Data de aceite: 2018-12-13 